Check for updates

Cite this: Chem. Commun., 2018, 54, 10347

Received 22nd May 2018,

Accepted 12th August 2018

DOI: $10.1039 / \mathrm{c} 8 \mathrm{cc} 04070 b$

rsc.li/chemcomm

\section{Electrochemical deposition of large-sized mesoporous nickel films using polymeric micelles $\dagger$}

\author{
Daisuke Baba, ${ }^{a}$ Jeonghun Kim, (D) ${ }^{b c}$ Joel Henzie, (D) *d Cuiling Li, ${ }^{d}$ Bo Jiang, ${ }^{d}$ \\ Ömer Dag, (D) e Yusuke Yamauchi (D) *cf and Toru Asahi*a
}

\begin{abstract}
Stable mesoporous nickel (Ni) films can be prepared using polystyrene-b-poly-(oxyethylene) (PS-b-PEO) micelles as sacrificial templates. In this method, positively charged Ni precursors form hydrogen bonds with the PEO segments of the micelles, which are then co-electrodeposited on the surface of a working electrode. Changing the applied voltage during electrodeposition modifies the deposition rate and ultimately controls the architecture of the mesoporous Ni film.
\end{abstract}

Mesoporous metal films are attractive architectures for electrochemical applications because they have ultra-large surface areas, high electrical conductivities and numerous exposed catalytic active sites. ${ }^{1}$ These features make them useful as porous electrodes in electrocatalytic devices, batteries and sensors. Mesoporous metal films have typically been synthesized by reducing metal precursors on lyotropic liquid crystal (LLC) templates. ${ }^{2,3}$ For example, LLCs can serve as molds to assemble lamellar and 2D hexagonal mesostructures composed of platinum (Pt), bismuth (Bi), nickel (Ni) and cobalt (Co) via electrodeposition. ${ }^{4,5}$ And mesoporous Pt films with large roughness factors have been electrodeposited onto microelectrodes, demonstrating the benefits of high surface

\footnotetext{
${ }^{a}$ Faculty of Science and Engineering, Waseda University, 3-4-1 Okubo, Shinjuku, Tokyo 169-8555, Japan. E-mail: tasahi@waseda.jp

${ }^{b}$ College of Chemistry and Molecular Engineering, Qingdao University of Science and Technology, Qingdao 266042, China

${ }^{c}$ School of Chemical Engineering and Australian Institute for Bioengineering and Nanotechnology (AIBN), The University of Queensland, Brisbane, QLD 4072, Australia.E-mail: y.yamauchi@uq.edu.au

${ }^{d}$ International Center for Materials Nanoarchitectonics (WPI-MANA), National Institute for Materials Science (NIMS), 1-1 Namiki, Tsukuba, Ibaraki 305-0044, Japan. E-mail: HENZIE.Joeladam@nims.go.jp

${ }^{e}$ Bilkent University, Department of Chemistry and UNAM-National Nanotechnology Research Center and Institute of Material Science and Nanotechnology, 06800, Ankara, Turkey

${ }^{f}$ Department of Advanced Materials Engineering for Information and Electronics, Kyung Hee University, 1732 Deogyeong-daero, Giheung-gu, Yongin-si, Gyeonggi-do, 17104, Republic of Korea

$\dagger$ Electronic supplementary information (ESI) available: SEM and HRTEM images, XRD, XPS and electrochemical characterization. See DOI: 10.1039/c8cc04070b
}

area and efficient mass transport characteristics in electrochemistry and electroanalysis. ${ }^{5}$ Our group recently demonstrated a new method to generate mesoporous metal films using polymeric micelles. Various metal precursor ions including $\mathrm{Pt}, \mathrm{Au}$, and $\mathrm{Rh}$ adsorb to the surface of the micelles, then electrochemical deposition is used to drive the micelles onto the surface of the working electrode while co-depositing the metal film. ${ }^{6-8}$ The diameters of the pores are tunable by combining various surfactants and organic solvents. ${ }^{9}$

The assembly of large-area, well-ordered mesoporous metal films has mostly been limited to noble metals such as Pt, Pd and Au because their surface energies are relatively low, and the materials are less prone to oxidation. Mesostructuring noble metals improves their catalytic activities by increasing their surface area and active sites, but noble metals are very costly because they are not abundant in the Earth's crust. Modifying mesoporous synthesis techniques to create structures composed of Earth abundant metals such as nickel (Ni) is a key next step in the creation of inexpensive, large-area ordered mesoporous electrode films. ${ }^{10}$ However, working with $\mathrm{Ni}$ is challenging because its low reduction potential makes the material more susceptible to reactions with water and air. ${ }^{11}$ And oxidation impacts the electrodeposition process by making it more difficult to control the morphology over large areas.

In this study, we describe a method to prepare mesoporous Ni films via electrochemical deposition. By carefully pairing the electrolyte with the polymeric micelles and Ni precursor, it is possible to apply a potential that drives the co-deposition of $\mathrm{Ni}$-decorated micelles, generating a mesoporous architecture throughout the Ni film. The resulting mesoporous Ni film has a high surface area and can be used to detect micro-molar level concentrations of glucose. Additionally, by fixing the applied potentials in the sensing experiments, it is possible to determine glucose concentration without the filtration of interference agents such as uric acid, ascorbic acid and mannose. We envision these mesoporous $\mathrm{Ni}$ films as part of a non-invasive, wearable electrochemical sensor to detect the concentration of glucose. Ultimately, creating inexpensive and highly sensitive electrochemical devices to 
monitor glucose daily or even continuously may improve self-care and health outcomes for diabetics. ${ }^{12}$

To generate the mesoporous Ni films, the precursor solution was prepared by dissolving $10 \mathrm{mg}$ of the polystyrene- $b$-poly(oxyethylene) $\left(\mathrm{PS}_{(63000)}-b-\mathrm{PEO}_{(26000)}\right)$ in $3 \mathrm{~mL}$ of tetrahydrofuran (THF) solvent. Then $1.5 \mathrm{~mL}$ of ethanol, $1 \mathrm{~mL}$ of aqueous $80 \mathrm{mM}$ $\mathrm{Ni}\left(\mathrm{CH}_{3} \mathrm{COO}\right)_{2}$ and $2.5 \mathrm{~mL}$ of $0.5 \mathrm{M} \mathrm{H}_{2} \mathrm{SO}_{4}$ was added in sequence and the solution was stirred for 5 hours. Electrodeposition of the Ni-decorated micelle precursors was performed by using a $\mathrm{Ag} / \mathrm{AgCl}$ reference electrode, a Pt counter electrode and a Au-coated Si substrate $(3 \mathrm{~mm} \times 3 \mathrm{~mm})$ as the working electrode. Different potentials were applied to deposit the $\mathrm{Ni}$ films $(-1.45 \mathrm{~V},-1.40 \mathrm{~V}$ and $-1.35 \mathrm{~V}$ vs. $\mathrm{Ag} / \mathrm{AgCl})$, and the electrodeposition was typically complete after 2500 seconds. During the electrodeposition step, the color of the Au-coated Si substrate became gray. Upon electrodeposition the sample was removed from the electrolyte solution and washed with tetrahydrofuran (THF) and water.

Linear sweep voltammetry (LSV) was used for electrolyte solutions with and without sulfuric acid to investigate the influence of applied voltage on the electrodeposition of mesoporous Ni films (Fig. 1a). ${ }^{13}$ The LSV experiments show that sulfuric acid caused $\mathrm{Ni}^{2+}$ to reduce to $\mathrm{Ni}^{0}$ at approximately $-0.8 \mathrm{~V} v s$. $\mathrm{Ag} / \mathrm{AgCl}$. Sulfuric acid may also increase the ion conductivity of the solution. ${ }^{14}$ Applied potentials of $-1.45,-1.40$ and $-1.35 \mathrm{~V} \mathrm{vs.} \mathrm{Ag} / \mathrm{AgCl}$ were investigated to assess its effect on the morphology and thickness of the deposited films as shown in the SEM images (Fig. 1b-d). At $-1.40 \mathrm{~V}$ vs. $\mathrm{Ag} / \mathrm{AgCl}$ the mesopores were most observable (Fig. 1c). Under these conditions, the mesoporous film homogenously coated the substrate without any defects (i.e. perforations, bumps, etc.). The pore size distribution for the mesoporous Ni film was obtained via high resolution SEM images and had an average size of $\sim 52 \mathrm{~nm}$ (Fig. S1, ESI $\dagger$ ). Previous reports demonstrate that mesoporous structures are strongly dependent on the deposition rates of metals. ${ }^{15,16}$ Potential affects the magnitude
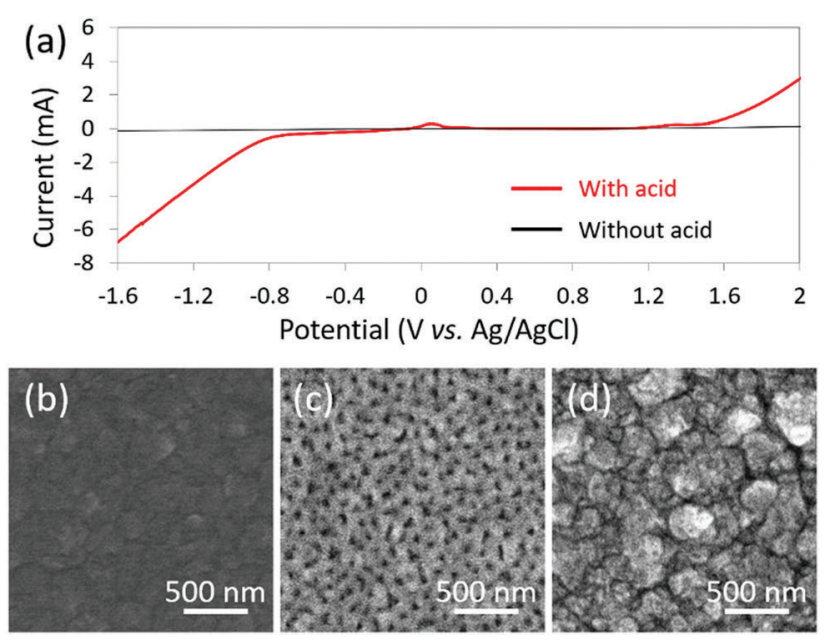

Fig. 1 (a) LSV of a precursor solution with and without sulfuric acid. The geometrical deposition area on the working electrode is $9 \mathrm{~mm}^{2}(3 \mathrm{~mm} \times$ $3 \mathrm{~mm}$ ). (b-d) SEM images of Ni films generated at various applied voltages: (b) $-1.35 \mathrm{~V}$, (c) $-1.4 \mathrm{~V}$, and (d) $-1.45 \mathrm{~V}$ vs. $\mathrm{Ag} / \mathrm{AgCl}$. of current passing through the working electrode. Larger negative voltages will generate higher currents, promoting a larger rate for the reduction of metal ions. Amperometric plots using different potentials demonstrate their influence on the deposition of mesoporous Ni films (Fig. S2, ESI $\dagger$ ). Smaller potentials (i.e. $-1.35 \mathrm{~V} v$ s. $\mathrm{Ag} / \mathrm{AgCl}$ ) generated a lower reduction rate, decreasing the Ni growth rate so much that only large Ni crystals formed and the micelles were not trapped in the metal to generate mesopores (Fig. 1b). A larger negative potential $(-1.45 \mathrm{~V}$ vs. $\mathrm{Ag} / \mathrm{AgCl})$ caused random nucleation and grain growth on the substrate, generating bumpy Ni films with no noticeable mesopores (Fig. 1d).

As a control experiment, Ni deposition was also performed without adding polymeric micelles to the electrolyte solution. $\mathrm{Ni}$ films were deposited under these conditions, but SEM observations show that no porous structures formed, as expected, proving that the polymeric micelles play a critical role in the formation of the mesopores. In pure THF, the PS- $b$ PEO block copolymer completely dissolves as a unimer and does not scatter light (Fig. 2a1). The addition of ethanol and aqueous solutions causes the solution to become cloudy and slightly opaque, indicating the formation of the polymeric micelles as illustrated by the Tyndall effect (Fig. 2a2). Upon addition of $\mathrm{Ni}\left(\mathrm{CH}_{3} \mathrm{COO}\right)_{2}$ the average diameter of micelles decreased from ca. 68 to ca. 25 nm (Fig. 2b1, b2 and Fig. S3, $\mathrm{ESI} \dagger$ ). Our previous report showed that the same phenomenon is caused by a change in the charge of the micelle surface. ${ }^{6}$ After adding $\mathrm{Ni}\left(\mathrm{CH}_{3} \mathrm{COO}\right)_{2}$ nickel precursor, the surface charge of the polymer micelle became positive due to the adsorption of positively-charged $\mathrm{Ni}$ ions in the PEO shells via hydrogen bonding (more detail on this phenomenon is given in later sections). In some parts, the micelles aggregated, indicating that the addition of $\mathrm{Ni}\left(\mathrm{CH}_{3} \mathrm{COO}\right)_{2}$ screened some repulsive interactions between the micelles (Fig. S4, ESI $\dagger$ ).

UV-Vis absorption spectra of various solutions were collected to gather information about the coordination sphere of the $\mathrm{Ni}^{2+}$ ions in the media. The spectra consisted of three relatively weak peaks at $\lambda=1200,700$, and $400 \mathrm{~nm}$ (Fig. 2c). The peaks at longer wavelengths correspond to the $\mathrm{d}-\mathrm{d}$ transitions of the $\mathrm{Ni}^{2+}$ species, specifically the ${ }^{3} \mathrm{~A}_{2 \mathrm{~g}}$ ground state to ${ }^{3} \mathrm{~T}_{2 \mathrm{~g}},{ }^{3} \mathrm{~T}_{1 \mathrm{~g}}(\mathrm{~F})$ and ${ }^{3} \mathrm{~T}_{1 \mathrm{~g}}(\mathrm{P})$ excited states that originate from d-orbital splitting of the $\mathrm{Ni}^{2+}$ ion in an octahedral ligand field, respectively. The peak positions are sensitive to the coordination sphere of the $\mathrm{Ni}^{2+}$ ion, and here the observed peak frequencies correspond to the $\left[\mathrm{Ni}\left(\mathrm{H}_{2} \mathrm{O}\right)_{6}\right]^{2+}$ ion. $^{17}$ The peak positions and relative absorption intensities of various combinations of precursor solutions were measured via UV-Vis spectrophotometry, and all solutions containing the Ni precursor appeared identical. This indicates that the $\mathrm{Ni}^{2+}$ ions are coordinated by 6 water molecules in all solutions.

The electrodeposition solution contained excess sulfuric acid to ensure that all of the acetate ions remained protonated. The acetate anion derived from the nickel salt is a weak base, but the charge of the $\left[\mathrm{Ni}\left(\mathrm{H}_{2} \mathrm{O}\right)_{6}\right]^{2+}$ ion is compensated by $\mathrm{HSO}_{4}{ }^{-}$ and $\mathrm{SO}_{4}{ }^{2-}$ ions. For the purpose of electrodeposition, having $\mathrm{Ni}^{2+}$ ions embedded in a water coordination sphere is likely to do two things: (i) it helps promote the micellization of the block 

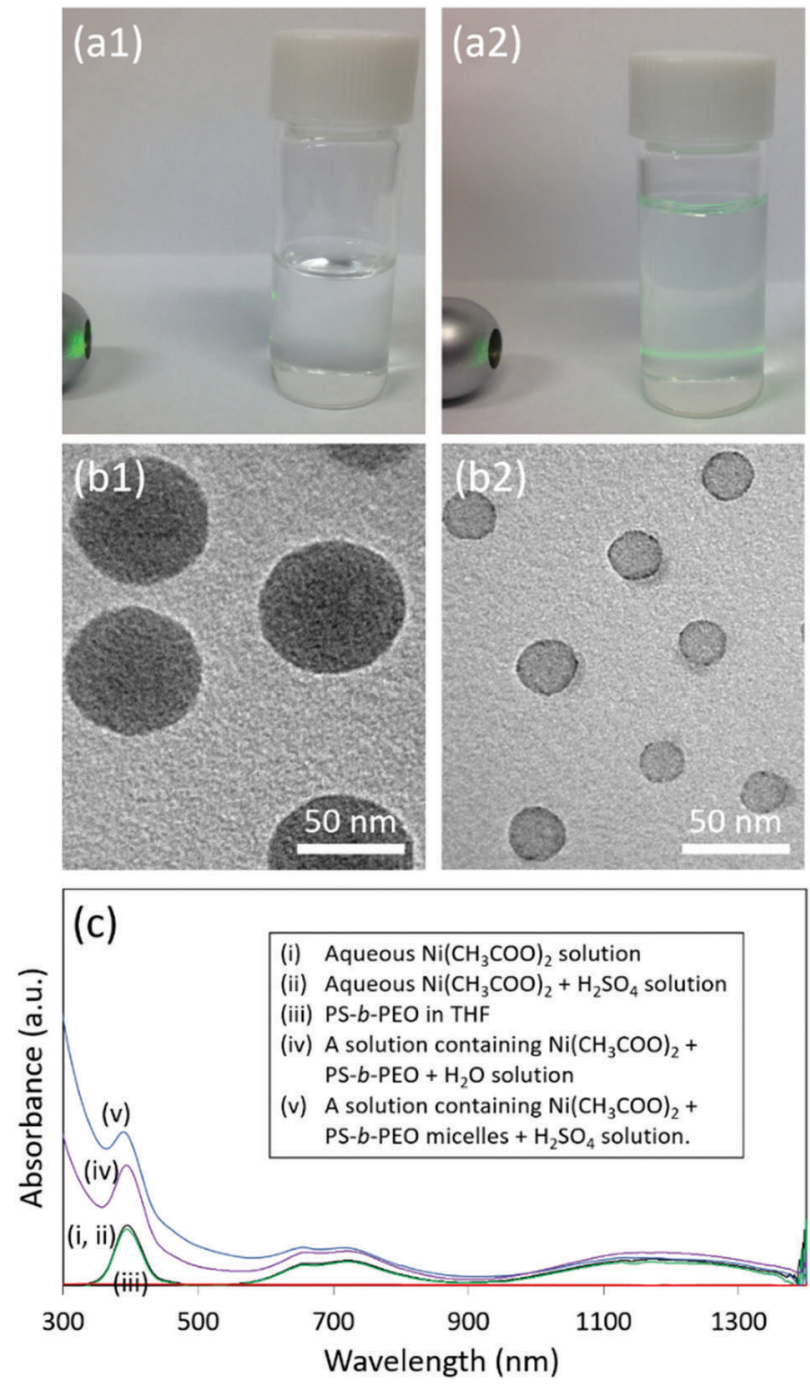

Fig. 2 (a) Optical micrographs demonstrating the emergence of the Tyndall effect in the electrolyte solution with different compositions: (a1) PS- $b$-PEO solution dissolved in THF and (a2) PS- $b$-PEO solution in THF after addition of $\mathrm{Ni}\left(\mathrm{CH}_{3} \mathrm{COO}\right)_{2}$ precursor. (b) TEM images: (b1) PS- $b$-PEO solution dissolved in THF and (b2) PS- $b$-PEO solution in THF after the addition of the $\mathrm{Ni}\left(\mathrm{CH}_{3} \mathrm{COO}\right)_{2}$ precursor. (c) UV/Vis-NIR spectra of different solutions used in the experiments.

copolymer, and perhaps more importantly (ii) it enhances hydrogen bonding interactions between the hydrophilic poly(ethylene oxide) shell of the micelles to load more $\left[\mathrm{Ni}\left(\mathrm{H}_{2} \mathrm{O}\right)_{6}\right]^{2+}$ ions on the surface of the micelles. ${ }^{18}$ An applied potential generates an electromotive force to drive the micelles toward the electrode surface, where reduction and electrodeposition of $\mathrm{Ni}^{0}$ takes place. The water coordination sphere and metal ion-surfactant interactions collectively enable the formation of mesostructured Ni films on the electrode surface.

The crystallinity of the electrodeposited mesoporous Ni films was examined via in-plane X-ray diffraction (XRD) (Fig. S5a, $\mathrm{ESI} \dagger)$. The peak at $44.6^{\circ}$ matched the $\mathrm{Ni}(111)$ crystal plane and showed the high crystallinity of the mesoporous Ni film. The average crystallite size was estimated to be $\sim 14 \mathrm{~nm}$ using the Scherrer equation. Surface chemical analysis was also carried out via X-ray photoelectron spectroscopy (XPS) (Fig. S5b, ESI $\dagger$ ). From the survey spectrum, metallic nickel atoms can be clearly observed on the film surface. The $\mathrm{Ni} 2 \mathrm{p}_{3 / 2}$ spectrum had three peaks matching $\mathrm{Ni}(852.8 \mathrm{eV}), \mathrm{NiO}(854.6 \mathrm{eV})$ and $\mathrm{Ni}_{2} \mathrm{O}_{3}$ $(856.5 \mathrm{eV})$. The XPS results indicate that the surface Ni atoms are likely oxidized in the atmosphere or in solution.

The most advantageous point of electrochemical deposition is that we can precisely control the film thickness by changing the applied deposition times. With the gradual increase of the deposition times, the film thickens (Fig. S6, ESI $\dagger$ ) and the deposited weight of $\mathrm{Ni}$ increased proportionally. The rate of film growth was $\sim 90 \mathrm{~nm} \min ^{-1}$ at $-1.40 \mathrm{~V} v s$. Ag/AgCl. This corresponded to a rate of $4.0 \times 10^{-5} \mathrm{mg} \mathrm{min}{ }^{-1}$, which was confirmed by the careful measurement of the samples using a sensitive microbalance (Fig. S7, ESI $\dagger$ ). Even though the deposition times were different, the same mesoporous structure was formed in all the films (Fig. S6, ESI $\dagger$ ).

The mesoporous Ni film was measured via cyclic voltammetry (CV) in aqueous $1 \mathrm{M} \mathrm{KOH}$ containing $10 \mathrm{mM}$-glucose. In the $\mathrm{CV}$ curves (Fig. 3a), the anodic peak at $0.4 \mathrm{~V}$ corresponds to the oxidation of glucose. ${ }^{19}$ It is known that $\mathrm{NiOOH}$ can oxidize glucose in alkaline solutions, for the formation of gluconolactone. The mesoporous surface of the Ni film electrode provides numerous active sites to drive this reaction. As shown in Fig. S8 (ESI $\dagger$ ), the peak intensity is proportional to the square root of scan rate. According to the Randles-Sevcik equation, our results indicate that the reaction is reversible and the electrode is limited by the diffusion of glucose to the electrode surface. ${ }^{20}$

To selectively sense glucose, we examined the role of applied potentials on sensitivity in the presence of various interference agents found in human sweat. Chronoamperometry was performed at different voltages including $0.1,0.2,0.3,0.4$, and $0.5 \mathrm{~V}$ vs. $\mathrm{Ag} / \mathrm{AgCl}$ in a three-electrode cell $\left(8 \mathrm{~cm}^{3}\right)$. The current was stable after 200 seconds, and each analyte solution was added to the stirred cell while the current response was recorded. From the current response, the current density was calculated using the geometrical surface area of the electrode. Fig. 3b shows a summary of the potential-dependent response toward glucose and the various interference agents. The relative current responses were calculated by fixing the response of glucose to $100 \%$. From Fig. $3 \mathrm{~b}$, it is clear that $0.4 \mathrm{~V} v s$. $\mathrm{Ag} / \mathrm{AgCl}$ potential is optimal for selective sensing of glucose.

To investigate the relationship between the glucose concentration and current, chronoamperometry was performed again at $0.4 \mathrm{~V} v s$. $\mathrm{Ag} / \mathrm{AgCl}$ with a three-electrode cell $\left(8 \mathrm{~cm}^{3}\right)$. Once the current was stable ( $\sim 200$ seconds), $0.1 \mathrm{~mL}$ of $80 \mathrm{mM}$ glucose in $1 \mathrm{M} \mathrm{KOH}$ was added to the cell (since the electrolyte volume was $8 \mathrm{~cm}^{3}$, the glucose concentration was increased by $1 \mathrm{mM}$ ). Then $0.1 \mathrm{~mL}$ of glucose solution was added to the reaction every 100 seconds for 10 times total. Fig. 3c shows the current response over time as glucose is added to the cell. We also examined the current response of the nonporous Ni foil for a comparison. The current clearly increased immediately after the addition of glucose, then the current became stable as the solution was completely mixed. The behaviour of the film did not change after each addition of glucose, indicating that glucose oxidation on the surface of the 

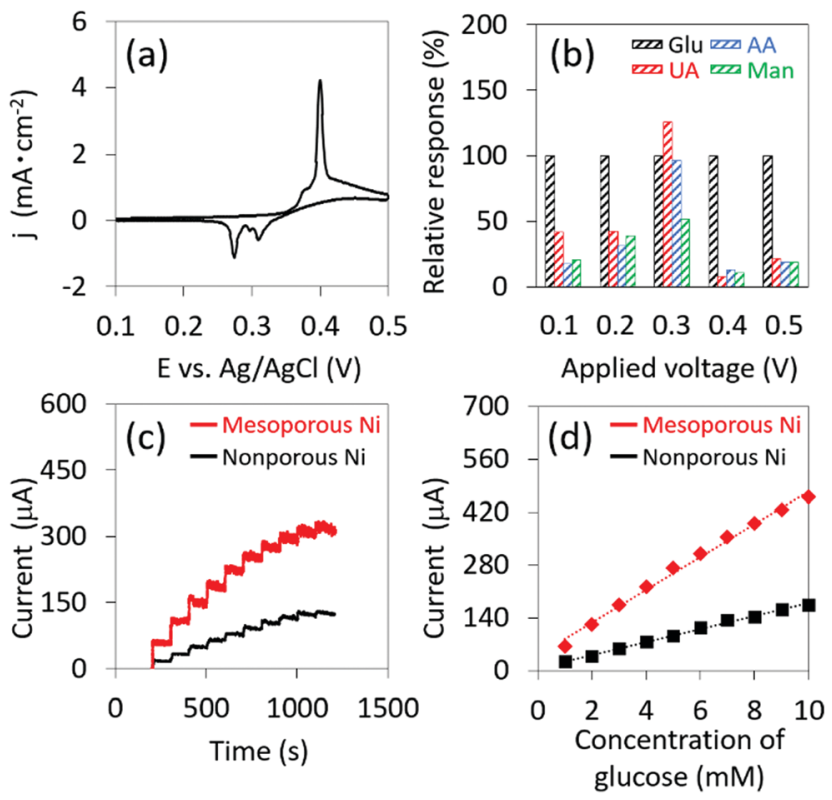

Fig. 3 (a) $\mathrm{CV}$ curves measured in aqueous $1 \mathrm{M} \mathrm{KOH}$ in the presence of $10 \mathrm{mM}$ glucose using the mesoporous $\mathrm{Ni}$ film as the working electrode. (b) Potential dependent current response toward $1 \mathrm{mM}$ glucose and various interfering agents including $0.1 \mathrm{mM}$ uric acid (UA), $0.1 \mathrm{mM}$ ascorbic acid (AA), and $0.1 \mathrm{mM}$ mannose (Man). (c) The dynamic sensing response of the mesoporous $\mathrm{Ni}$ film and nonporous $\mathrm{Ni}$ surface upon successive additions of $1 \mathrm{mM}$ glucose solution. (d) Corresponding relationship between the amperometric response and the glucose concentration.

mesoporous Ni film was quite stable. By comparing the current response after each addition of glucose, the relationship between the glucose concentration and current is shown in Fig. 3d. Chronoamperometry using 1-10 mM glucose also demonstrated the linear relationship between the glucose concentration and current. At each concentration range, the current response of the mesoporous Ni film was 2.5 times higher than a nonporous $\mathrm{Ni}$ electrode. Table S1 (ESI $\dagger$ ) summarizes previous literature describing glucose oxidation with nanostructured $\mathrm{Ni}$ to put our experiments into context. The sensitivity to glucose was 43.6 $\mu \mathrm{A} \mathrm{mM}^{-1}$ and $1.09 \mathrm{~mA} \mathrm{mM}{ }^{-1} \mathrm{~cm}^{-2}$, indicating that our mesoporous films perform better compared with the present literature. ${ }^{21-24}$ It is clear that the mesoporous morphology of the Ni films is responsible for boosting the oxidation of glucose.

In conclusion, we succeeded in preparing mesoporous $\mathrm{Ni}$ films with uniformly sized pores by using polymeric micelles as the structure directing agent and $\mathrm{Ni}\left(\mathrm{CH}_{3} \mathrm{COO}\right)_{2}$ as the Ni precursor. $\mathrm{Ni}^{2+}$ ions are embedded in a water coordination sphere that assists in the micellization of the block copolymer and enhances the hydrogen bonding interactions between the hydrophilic poly(ethylene oxide) blocks of the micelle with the $\mathrm{Ni}^{2+}$ species. The electrodeposition rate was found to be quite important in the formation of high quality mesoporous structures within the Ni films. In addition, selecting the appropriate potentials allowed us to minimize the influence of common interference agents and accurately determine the concentration of glucose in the solution. These mesoporous $\mathrm{Ni}$ films are easy to prepare, and may function as porous electrodes in a non-invasive, wearable electrochemical sensor that can monitor glucose concentrations in human sweat. Inexpensive and highly sensitive electrochemical devices to monitor glucose continuously should improve self-care and health outcomes for people with diabetes.

Characterization methods: The samples were observed by using a scanning electron microscope (Hitachi SU8000). The SEM images were obtained at the accelerating voltage of $15 \mathrm{kV}$. The crystal structure was measured via XRD (RIGAKU SmartLab). X-ray photoelectron spectroscopic measurements were conducted by using a JPS-9010TR (JEOL) instrument with an Mg K $\alpha$ X-ray source. Cyclic voltammetry (CV) and chronoamperometry data were recorded by using a CHI 842B electrochemical analyzer (CH Instruments).

\section{Conflicts of interest}

There are no conflicts to declare.

\section{Notes and references}

1 (a) V. Malgras, H. Ataee-Esfahani, H. Wang, B. Jiang, C. Li, K. C.-W. Wu, J. H. Kim and Y. Yamauchi, Adv. Mater., 2016, 28, 993; (b) C. Li, M. Iqbal, J. Lin, X. Luo, B. Jiang, V. Malgras, K. C.-W. Wu, J. Kim and Y. Yamauchi, Acc. Chem. Res., 2018, DOI: 10.1021/acs.accounts.8b00119.

2 G. S. Attard, P. N. Bartlett, N. R. B. Coleman, J. M. Elliott, J. R. Owen and J. H. Wang, Science, 1997, 278, 838.

3 (a) Y. Yamauchi, A. Tonegawa, M. Komatsu, H. Wang, L. Wang, Y. Nemoto, N. Suzuki and K. Kuroda, J. Am. Chem. Soc., 2012, 134, 5100; (b) Y. Yamauchi, A. Takai, T. Nagaura, S. Inoue and K. Kuroda, J. Am. Chem. Soc., 2008, 130(16), 5426.

4 H. Luo, L. Sun, Y. Lu and Y. Yan, Langmuir, 2004, 20, 10218.

5 J. M. Elliott, P. R. Birkin, P. N. Bartlett and G. S. Attard, Langmuir, 1999, 15, 7411.

6 Y. Li, B. P. Bastakoti, V. Malgras, C. L. Li, J. Tang, J. H. Kim and Y. Yamauchi, Angew. Chem., Int. Ed., 2015, 54, 11073.

7 C. Li, Ö. Dag, T. D. Dao, T. Nagao, Y. Sakamoto, T. Kimura, O. Terasaki and Y. Yamauchi, Nat. Commun., 2015, 6, 6608.

8 B. Jiang, C. Li, Ö. Dag, H. Abe, T. Takei, T. Imai, M. S. A. Hossain, M. T. Islam, K. Wood, J. Henzie and Y. Yamauchi, Nat. Commun., 2017, 8, 15581.

9 B. Jiang, C. Li, J. Tang, T. Takei, J. Kim, Y. Ide, J. Henzie, S. Tominaka and Y. Yamauchi, Angew. Chem., Int. Ed., 2016, 55, 10037.

10 (a) T. Sun, L. Xu, Y. Yan, A. A. Zakhidov, R. H. Baughman and J. Chen, ACS Catal., 2016, 6, 1446; (b) M. Ledendecker, G. Clavel, M. Antonietti and M. Shalom, Adv. Funct. Mater., 2015, 25, 393; (c) J. Wang, H. X. Zhong, Y. L. Qin and X. B. Zhang, Angew. Chem., Int. Ed., 2013, 52, 5248.

11 P. A. Nelson, J. M. Elliott, G. S. Attard and J. R. Owen, Chem. Mater., $2002,14,524$.

12 D. Bruen, C. Delaney, L. Florea and D. Diamond, Sensors, 2017, 17, 1866.

13 C. Li, B. Jiang, Z. Wang, Y. Li, M. S. A. Hossian, J. H. Kim, T. Takei, J. Henzie, Ö. Dag, Y. Bando and Y. Yamauchi, Angew. Chem., Int. Ed., 2016, 55, 12746.

14 H. Majima, E. Peters, Y. Awakura and S. K. Park, Metall. Trans. B, 1987, 18, 41.

15 G. S. Attard, C. G. Gçltner, J. M. Corker, S. Henke and R. H. Templer, Angew. Chem., Int. Ed., 1997, 36, 1315.

16 J. M. Elliott, G. S. Attard, P. N. Bartlett, N. R. B. Coleman, D. A. S. Merckel and J. R. Owen, Chem. Mater., 1999, 11, 3602.

17 A. B. P. Lever, Inorganic Electronic Spectroscopy, Elsevier, New York, 1968. 18 Ö. Celik and Ö. Dag, Angew. Chem., Int. Ed., 2001, 40, 3800.

19 K. E. Toghill and R. G. Compton, Int. J. Electrochem. Sci., 2010, $5,1246$.

20 A. L. Rinaldi and R. Carballo, Sens. Actuators, B, 2016, 228, 43.

21 A. Safavi, N. Maleki and E. Farjami, Biosens. Bioelectron., 2009, 24, 1655. 22 A. Salimi and M. Roushani, Electrochem. Commun., 2005, 7, 879.

23 Y. Liu, H. Teng, H. Hou and T. You, Biosens. Bioelectron., 2009, 24, 3329.

24 K. E. Toghill, L. Xiao, M. A. Phillips and R. G. Compton, Sens. Actuators, B, 2010, 147, 642 . 